\section{A rapid method for isolation of low-molecular-weight RNA from Arabidopsis using low salt concentration buffer}

\author{
Han Cheng, Jing Gao, Ze-Wei An, \\ Hua-Sun Huang \\ Key Laboratory of Rubber Biology, \\ Ministry of Agriculture, Rubber Research \\ Institute, Chinese Academy of Tropical \\ Agricultural Science, Danzhou, Hainan, \\ P.R. China
}

\begin{abstract}
We have developed a rapid extraction method using low salt concentration buffer for the isolation of RNA from Arabidopsis tissues. The method was quick and efficient, and the small scale extraction process took no more than one hour, while yield and RNA quality were comparable with those previously reported. The low-molecular-weight (LMW) RNA isolated using this method was high quality, abundant in small RNA and free of high molecular weight RNA. This method can be used to extract low-molecular-weight RNA for the purpose of small RNA cloning and detection, and library construction.
\end{abstract}

\section{Introduction}

Low-molecular-weight (LMW) RNA, which includes 20- to 24-nt small interfering RNA ${ }^{1}$ and microRNA, ${ }^{2,3}$ plays an important role in regulating gene expression by a mechanism known as RNAi (RNA interference or gene silencing). Though much attention has been devoted to an analysis of the functions of these small RNAs, an extraction protocol has not been optimized. Currently, small RNA extraction and detection methods fall into two major strategies. The first is to isolate total RNA and run on a polyacrylamide gel, then recover the small RNA from the gel or detect them using Northern blotting. However, this method needs to load large amounts of total RNA and often causes irregular banding due to overloading. Therefore, a prefered strategy is to use the LMW RNA for separating and detecting small RNA. The LMW RNA extraction protocol usually includes stepwise precipitation to eliminate DNA and high-molecular-weight (HMW) RNA, which makes the extraction process tedious and time-consuming. Besides, the lengthy extraction process is liable to cause RNA degradation.

Plant tissues are rich in polysaccharides, polyphenols and other secondary metabolites which make the isolation of good-quality LMW RNA more difficult. ${ }^{4.7}$ The secondary metabolites can interfere with nucleic acid separation and result in poor yield of LMW RNA. A cetyltrimethylammonium bromide (CTAB) based method combined with PVP could overcome this problem. ${ }^{8}$ However, even this optimized protocol took no less than two days. Another choice is to use the commercial kits; but most of them are expensive. Therefore, there is the need for a quick and simple method to isolate LMW RNA.

Here we report a novel and efficient method for the extraction of LMW RNA from plant tissues, which is convenient and less time consuming than current methods. This method also adopts CTAB and polyvinyl pyrrolidone (PVP) to eliminate secondary metabolite contaminations. But the key point is using low salt concentration (LSC) extraction buffer containing 0.4 M sodium acetate. In the cells, DNA and HMW RNA are bound to proteins and form complexes termed DNP and RNP which do not dissolve in the low salt concentration buffer, ${ }^{9}$ while the LMW RNA remains soluble. Thus, LMW RNA can be separated from DNA and HMW RNA during centrifuging and no extra eliminating steps were needed. Then the LMW RNA in the LSC buffer can be easily recovered. In this study, we used this method to extract LMW RNA from different tissues of Arabidopsis and obtained good results. In addition, the utility of the extracted LMW RNA was further investigated.

\section{Materials and Methods}

\section{Plants}

Arabidopsis plants (Col-0) were grown in a controlled growth chamber at $23 \pm 1^{\circ} \mathrm{C}$ with a $16 \mathrm{~h}$ light/8 h dark photoperiod. The plant samples were harvested at four weeks old and frozen immediately in liquid nitrogen.

\section{Solutions}

\section{LSC Extraction buffer \\ $2 \%$ CTAB \\ $2 \%$ PVP \\ $0.4 \mathrm{M} \mathrm{NaAC}$ (pH 5.2) \\ $20 \mathrm{mM}$ EDTA \\ $2 \% \beta$-ME (add just before use)}

Washing buffer (pH 7.4)

$25 \mathrm{mM}$ Tris.Cl

$10 \mathrm{mM}$ EDTA

$80 \%$ ethanol

TE buffer (pH 8.0)

$10 \mathrm{mM}$ Tris

$1 \mathrm{mM}$ EDTA
Correspondence: Hua-Sun Huang, Rubber Research Institute, Chinese Academy of Tropical Agricultural Science, Danzhou, Hainan, 571737, P. R. China. E-mail: huasunhuang@gmail.com

Key words: low-molecular-weight RNA, low salt concentration buffer, Arabidopsis.

Contributions: HC, experimental design, sample collection, RNA extraction, Northern blotting; JG, RNA extraction; ZA, RNA PAGE; HH, experiment instruction, manuscript preparation.

Acknowledgments: we thank Dr. Tang Chaorong for helpful discussion. This work was supported by National Natural Science Foundation of China (30960319).

Conflict of interest: the authors report no conflicts of interest.

Received for publication: 23 January 2010.

Revision received: 26 July 2010 .

Accepted for publication: 27 July 2010.

This work is licensed under a Creative Commons Attribution 3.0 License (by-nc 3.0).

(c) Copyright H. Cheng et al., 2010

Licensee PAGEPress, Italy

International Journal of Plant Biology 2010; 1:e14 doi:10.4081/pb.2010.e14

PCI (Phenol-chloroform-isoamylalcohol, 25:24:1)

$50 \mathrm{~mL}$ water saturated phenol

$48 \mathrm{~mL}$ chloroform

$2 \mathrm{~mL}$ isoamylalcohol

Total volume $100 \mathrm{~mL}$

$\mathrm{Cl}$ (chloroform-isoamlalcohol, 24:1)

$96 \mathrm{~mL}$ chloroform

$4 \mathrm{~mL}$ isoamylalcohol

Total volume $100 \mathrm{~mL}$

Small scale extraction

Step 1: grind $50 \mathrm{mg}$ tissue into fine powder;

Step 2: transfer the sample into $0.5 \mathrm{~mL}$ LSC extraction buffer and vortex vigorously for $1 \mathrm{~min}$;

Step 3: incubate at $65^{\circ} \mathrm{C}$ for 10 min with occasionally swirling;

Step 4: centrifuge at $20,000 \mathrm{~g}$ for $10 \mathrm{~min}$ at $4^{\circ} \mathrm{C}$;

Step 5: transfer the upper liquid phase (about $400 \mu \mathrm{L})$ to new tube;

Step 6: add $200 \mu \mathrm{L}$ of isopropanol and mix well;

Step 7: transfer the mixture into an RNase free silica spin column (Tiangen, Beijing, China), and centrifuge for $30 \mathrm{sec}$ at $6,500 \mathrm{~g}$;

Step 8: add $700 \mu \mathrm{L}$ washing buffer and centrifuge for $30 \mathrm{sec}$ at 6,500g;

Step 9: discard the flow through and repeat step 8;

Step 10: centrifuge for $1 \mathrm{~min}$ at $12,000 \mathrm{~g}$; 
Step 9: add $50 \mu \mathrm{L}$ TE buffer onto the silica membrane and elute the LMW RNA into a new RNase free tube.

\section{Large scale extraction}

Step 1: grind $1 \mathrm{~g}$ tissue into fine powder;

Step 2: transfer the sample into $10 \mathrm{~mL}$ LSC extraction buffer and incubate at $65^{\circ} \mathrm{C}$ for 10 min, then place the tube on ice;

Step 3: add $10 \mathrm{~mL}$ PCI, vortex vigorously for $1 \mathrm{~min}$;

Step 4: centrifuge at $30,000 \mathrm{~g}$ for $10 \mathrm{~min}$ at $4^{\circ} \mathrm{C}$;

Step 5: transfer the supernatant into new tube;

Step 6: add $10 \mathrm{~mL} \mathrm{CI}$, vortex and centrifuge at $30,000 \mathrm{~g}$ for $10 \mathrm{~min}$ at $4^{\circ} \mathrm{C}$;

Step 7: recover the supernatant, add $10 \mathrm{~mL}$ ice cooled isopropanol and incubate at $-20^{\circ} \mathrm{C}$ for more than $1 \mathrm{~h}$;

Step 8: centrifuge at $30,000 \mathrm{~g}$ for $20 \mathrm{~min}$ at $4^{\circ} \mathrm{C}$, and discard the supernatant;

Step 9: re-suspend the precipitate with $0.5 \mathrm{mlL}$ LSC buffer and transfer to a $1.5 \mathrm{ml}$ tube;

Step 10: extract the sample sequentially with $0.5 \mathrm{~mL} \mathrm{PCI}$ and $\mathrm{CI}$, and collect the supernatant;

Step 11: add $0.5 \mathrm{~mL}$ isopropanol and incubate at $-20^{\circ} \mathrm{C}$ for more than $30 \mathrm{~min}$;

Step 12: centrifuge at $20,000 \mathrm{~g}$ for $10 \mathrm{~min}$ at $4^{\circ} \mathrm{C}$, and discard the supernatant;

Step 13: wash the precipitant twice with $80 \%$ ethanol, and dissolve in $50 \mu \mathrm{L}$ TE buffer.

\section{Low-molecular-weight RNA poly- acrylamide gel electrophoresis and Northern blotting}

For LMW RNA electrophoresis, $3 \mu \mathrm{g}$ LMW RNA of each sample were denatured and loaded onto urea (8\%) 15\% polyacrylamide gels. After electrophoresis, the gels were stained with $1 \mathrm{mg} / \mathrm{L}$ ethidium bromide (EB) for $30 \mathrm{~min}$ and visualized under ultraviolet light.

For Northern blotting, about 30 microgram LMW RNA was run on 15\% denaturing polyacrylamide gel electrophoresis (PAGE) gel until the bromophenol blue band reached the bottom. Then the LMW RNA was transferred to nylon membrane using semi-dry transfer apparatus (Bio-Rad, Hercules, CA, USA). The hybridization procedure was carried out as described, ${ }^{10}$ except use of the 5 '-digoxigenin labeled probe. After hybridization and 3 washes, the blot was detected using the DIG-High Prime DNA Labeling and Detection Starter Kit II (Roche, Basel, Switzerland).

\section{Results and Discussion}

LMW RNA was extracted from the leaf, root, stem and inflorescence tissues of Arabidopsis, and in each case high quality LMW RNA was obtained. Spectrophotometry was used for LMW RNA quantification and quality checking by calculating the A260/A230 and A260/A280 ratio. These ratio values fell into the range from 1.6 to 2.2 (Supplementary Tables 1 and 2), which were almost the same as those of previously reported studies ${ }^{8}$ and indicated low polysaccharide and protein contamination. The yield of our method is about $50 \mu \mathrm{g} / \mathrm{g}$ FW for Arabidopsis (Supplementary Table 1) and was marginally lower than that reported. ${ }^{8}$ LMW RNA samples of all these tissues were subjected to $15 \%$ denaturing polyacrylamide gel electrophoresis (PAGE), and distinct 5.8S and $5 \mathrm{~S}$ ribosomal bands were sharp and intense, indicating good recovery rate and intactness (Figure 1). In addition, no extra band existed above the LMW band (Figure 2A), indicating HMW RNA and DNA were eliminated. This conclusion was also proved by $2 \%$ agarose gel electrophoresis.

To check the downstream applicability of the LMW RNA extracted using this method, Northern blotting was carried out for the expression analysis of specific miRNA. Here we analyzed the expression of one Arabidopsis miRNA, AtMIR319C (miRNA sequence, 5'UUUGGACUGAAGGGAGCUCC-3') which had been previously revealed to express at moderate levels in leaves, roots, and young seedling but strongly in stems and inflorescence. ${ }^{10}$ After electrophoresis, the gel was stained with ethidium bromide and visualized. As shown in Figure 2A, a distinct smear appeared between the indicator bands of xylene cyanol FF and bromophenol blue, which was about the size of 20-60 nt. This range covered almost all of the known small RNA species. MIR319C expression was detected in all LMW RNA samples, and was particularly abundant in those of stem and inflorescence, which was consistent with a previous report ${ }^{10}$ (Figure 2B). These results demonstrated the LMW RNA extracted by this method contained abundant small RNA and could be used for further applications, such as expression analysis.

In the routine nucleic acid extraction recipe, a high concentration sodium chloride (usually $1.4 \mathrm{M}$ ) is included for the purpose of dissolving the protein-nucleic acid complexes. Success ively extracting liver tissue with gradient concentrations of $\mathrm{NaCl}$ resulted in different recovery rates for DNP and RNP, ${ }^{9}$ which suggested that DNA, HMW RNA and LMW RNA have different solubilities in certain concentrations of salt buffers. We tested several kinds of salts and found $0.4 \mathrm{M} \mathrm{NaAC}$ was the most effective for separating LMW RNA from DNA and HMW RNA. Using low concentrations of NaAC, we developed a fast and efficient method to isolate LMW RNA from Arabidopsis tissue. In this method, DNA and HMW RNA were precipitated during the first centrifuging and LMW RNA remained in the supernatant. Therefore, the next step was just to recover the LMW RNA from the supernatant. Combined with the use of a silica

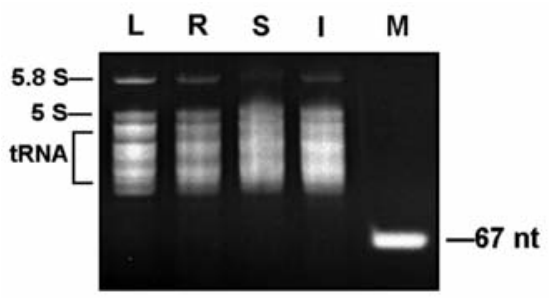

Figure 1. Low-molecular-weight (LMW) RNA (3 g) samples from different Arabidopsis tissues were run on urea $(8 \%)$ $15 \%$ polyacrylamide electrophoresis gels $(20$ volts $/ \mathrm{cm}, 2 \mathrm{~h})$, and stained with ethidium bromide (EB). Lane $L$, leaf; Lane $R$, root; Lane S, stem; Lane I, inflorescence; Lane M, 67-nt DNA molecular marker.

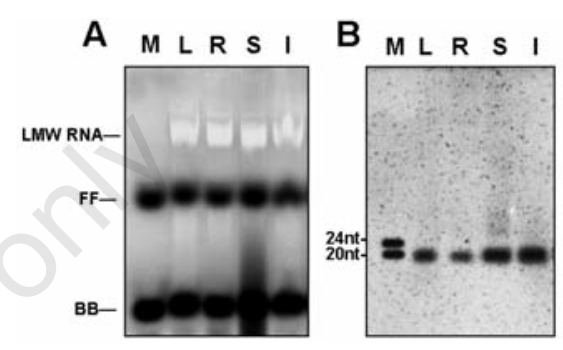

Figure 2. Northern blotting of Arabidopsis microRNA MIR319C. 30 microgram LMW RNA extracted from different Arabidopsis tissues using LSC buffer were run on $15 \%$ denaturing urea PAGE gel (20 volts $/ \mathrm{cm}, 1 \mathrm{~h}$ ). (A) Photogram of ethidium bromide stained PAGE gel. (B) Blotting result using the 5'- digoxigenin labeled complement probe of MIR319C. Lane M, $10 \mathrm{pg} 20$ and $24 \mathrm{nt}$ digoxigenin labeled DNA marker; Lane L, leaf; Lane R, root; Lane S, stem; Lane I, inflorescence; LMW RNA, band of low-molecular-weight RNA; FF, band of xylene cyanol FF; BB, band of bromophenol blue.

spin column for small scale extraction and double precipitation for large scale, this method produced LMW RNA with good quality and low polysaccharide and protein contamination. The NaAC concentration in LSC buffer was the key factor influencing the final quality of LMW RNA. We tested NaAC concentration of $0.1 \mathrm{M}$ to $0.6 \mathrm{M}$ and found the best results could be obtained at $0.4 \mathrm{M}$. Higher concentration led to DNA contamination, while a lower concentration resulted in poor yield (data not show). This method can also be used for extracting LMW RNA from other plants (Supplementary Figure 1). For example, we have extracted LMW RNA from rubber tree using this method and constructed a microRNA library ( $Z W$ An, unpublished data, 2010).

In summary, we have developed a simple and fast extraction method for the isolation of LMW RNA from Arabidopsis tissues using LSC buffer. The method was quick and efficient, isolating LMW RNA from tissue in one step and 
no extra procedure was needed for the elimination of DNA and HMW RNA. The total extraction process took no more than one hour for small scale extraction, and even only three to four hours for large scale extraction, while the yield and RNA quality were comparable with those published. ${ }^{8}$ In addition, the LMW RNA isolated using this method was free of HMW RNA and abundant in small RNA. This method can be used for extracting LMW RNA for the purpose of small RNA cloning and detection, and library construction.

\section{References}

1. Hamilton A, Baulcombe D. A species of small antisense RNA in posttranscription- al gene silencing in plants. Science 1999;286:950-2.

2. Llave C, Kasschau KD, Rector MA, Carrington JC. Endogenous and silencingassociated small RNAs in plants. Plant Cell 2002;14:1605-19.

3. Reinhart BJ, Weinstein EG, Rhoades MW, et al. MicroRNAs in plants. Genes Dev 2002;16:1616-26.

4. Park W, Li J, Song R, et al. CARPEL FACTORY, a Dicer homolog, and HEN1, a novel protein, act in microRNA metabolism in Arabidopsis thaliana. Curr Biol 2002;12: 1484-95.

5. Lau NC, Lim LP, Weinstein EG, Bartel DP. An abundant class of tiny RNAs with probable regulatory roles in Caenorhabditis elegans. Science 2001;294:858-62.

6. Buhtz A, Springer F, Chappell L, et al.
Identification and characterization of small RNAs from the phloem of Brassica napus. Plant J 2008;53:739-49.

7. Chappell L, Baulcombe D, Molnár A. Isolation and cloning of small RNAs from virus-infected plants. Curr Protoc Microbiol 2006;Chap 16:Unit 16H.12.

8. Carra A, Gambino G, Schubert A. A cetyltrimethylammonium bromide-based method to extract low-molecular-weight RNA from polysaccharide-rich plant tissues. Anal Biochem 2007;360:318-20.

9. Griffin AC, Nye WN, et al. Tissue proteins and carcinogenesis; the effect of carcinogenic azo dyes on liver proteins. J Biol Chem 1948;176:1225-35.

10.Sunkar R, Zhu JK. Novel and stress-regulated microRNAs and other small RNAs from Arabidopsis. Plant Cell 2004;16:2001-19. 